\title{
Treatment of Kaposi's Sarcoma by Combination of Zinc Sulfate and Propranolol
}

\author{
Khalifa E. Sharquie ${ }^{1,2^{*}}$, Adil A. Noaimi ${ }^{1,2}$ \\ ${ }^{1}$ Department of Dermatology, College of Medicine, University of Baghdad, Baghdad, Iraq \\ ${ }^{2}$ Iraqi and Arab Board for Dermatology \& Venereology, Baghdad Teaching Hospital, Baghdad, Iraq \\ Email: *ksharquie@ymail.com, adilnoaimi@yahoo.com
}

How to cite this paper: Sharquie, K.E. and Noaimi, A.A. (2018) Treatment of Kaposi's Sarcoma by Combination of Zinc Sulfate and Propranolol. Journal of Cosmetics, Dermatological Sciences and Applications, 8, 249-255.

https://doi.org/10.4236/jcdsa.2018.84026

Received: July 11, 2018

Accepted: December 18, 2018

Published: December 21, 2018

Copyright $\odot 2018$ by authors and Scientific Research Publishing Inc. This work is licensed under the Creative Commons Attribution International License (CC BY 4.0).

http://creativecommons.org/licenses/by/4.0/

\begin{abstract}
Kaposi's sarcoma (KS) in Iraq has been reported as sporadic cases of elderly of Iraqi population but after exposure to depleted uranium radiation in early 1991, the frequency of the disease is increasing appearing in younger age with more wide spread and aggressive in nature. There is no satisfactory oral treatment to control this disease. The aim of the present work is to record a new regime of therapy using oral zinc sulfate and oral propanolol. Four patients with wide spread Kaposi's sarcoma (KS) were treated with oral and topical zinc sulfate solution and oral propranolol. The duration of treatment was between $6-12$ months and the response started few weeks and was obvious after one month. Most old lesions were resolved leaving post inflammatory hyperpigmentation and few lesions appeared during course of treatment.
\end{abstract}

\section{Keywords}

Kaposi’s Sarcoma, Treatment, Zincsulfate, Propranolol

\section{Introduction}

Kaposi's sarcoma (KS) is a vascular neoplasm with multicentric cutanenous and extracutaneous involvements. It is considered as a reactive hyperplasia but not than a neoplasm. Despite its name, it is no more classified as a sarcoma and it has prominent vascular growth and neovascularisation [1]. KS is commonly associated with herpes 8 infections and there is depression immunity [2]. Kaposi's sarcoma in Iraq has been sporadic disease of elderly [3] but after American attack and depleted uranium radiation exposure in early 1991, the incidence of the disease is increasing and its onset observed at younger age, more wide spread and aggressive with more morbidity and mortality. And all patients are negative for AIDS apart from few cases as a result of contamination of blood transfusion [4]. 
There are no therapy aiming to cure the disease but most drugs that are used hoping to ameliorate and stop the progression of the disease [1] [5].

Many topical treatments have been used like: radiotherapy, cryosurgery, laser, excisional surgery, intralesional injections with INF-alpha, vinblastine, vincrestine or bleomycin [1] [5] [6]. These treatments have been used to treat limited mucocutaneous disease and smaller lesions are more likely to respond. Other topical treatments like retinoids, Imiquimod 5\% cream applied 3 times weekly for 24 weeks [1] [5] [6].

Systemic cytotoxic drugs like: etoposide, bleomycin, doxorubicin, liposomal agents, vinblastine and vincrestine, Paclitaxel, gemcitabine, Interferon but unfortunately no one gives complete clearance and cure [1] [5] [6].

Propranolol has been used effectivelly treat infantile hemangioma (IH) as it works through the many mechanisms and as follow:

1) Inducing the vasoconstriction of the high-flow blood vessels feeding the IH tumor.

2) Inhibiting the vasculogenesis that happen in infantile haemangioma.

3) Inhibits catecholamine induced angiogenesis, over expression of several growth factors, such (VEGF), (MMP)-2, MMP-9 and interleukin (IL)-6. As these are associated with progression in proliferating $\mathrm{IH}$.

4) Propranolol also causes apoptosis of haemangioma-derived endothelial cells (It has been hypothesized that $\beta$-1 adrenoreceptor is one of the probable receptors involved in apoptosis and propranolol blocking the $\beta$-1 adrenoreceptor induces apoptosis at an increased rate [7].

Zinc sulfate has been applied to treat many skin diseases like viral warts [8], leishmaniasis [9], both through topical and oral intake as it has immunomodulator, antimicrobial, antioxidants and cytotoxic actions as zinc sulfate has many therapeutic functions like:

1) Zinc serves as a catalyst for enzymes responsible for DNA replication, gene transcription and RNA and protein synthesis. And at the cellular level, zinc is critical for cell survival and affects signal transduction, transcription and replication [10].

2) In high concentration, zinc has direct cytotoxic actionon the cells [10].

3) Zinc is essential for more than 300 metalloenzymes, including the antioxidant enzyme, superoxide dismutase and affects their conformity, stability and activity. Zinc is very important for several human functions, including growth and development, bone metabolism, neuropsychiatry and immune functions and healing of wounds [11] [12].

4) Zinc acts an indirect antioxidant action by inducing of some substances that work as the ultimate antioxidant and these substances are "etallothionein" a group of low molecular weight metal-binding proteins that can bind $5-7 \mathrm{gm}$ of zinc [12] [13].

5) Zinc serves as an integral action in neutrophils, peripheral blood monocytes, tissue macrophages (macrophage up taking and killing activity), and mast cells actions. These two neutrophil functions, phagocytosis and chemotaxis, are 
zinc dependant [10] [13].

6) Natural killer cell activitie are depressed in patients with zinc deficiency of and giving zinc to these patients will improve the functions of these cells [14].

7) Zinc has anti-apoptotic effect, as zinc is a potent inhibitor of endonucleases wich are the key constituents of the apoptotic machine [14].

8) Zinc and iron are the well-known trace elements which are associated with hair growth [15] as zinc is engaged in important functional activities in hair follicles [16]. In addition; zinc potently inhibits hair follicle regression and accelerates hair follicle recovery. There was good correlation between the $\mathrm{Zn}$ levels in hair and serum with the serum alkaline phosphatase activity [16].

Also topical zinc sulfate $25 \%$ - $50 \%$ solution had been used in many cases of localized Kaposi's sarcoma over long time and gave satisfactory results in suppression of activity of the disease and clearance of rash (Sharquie's 2000 personal communications).

Hence the aim of the present study is to record our experience in treatment of KS by oral with topical zinc sulfate and systemic propranolol through using their different mechanism of actions and functions.

\section{Patients and Methods}

Four cases with wide spread Kaposi's sarcoma were included in the present report, three males and one female, their ages ranged from 60 - 75 years and the duration of the disease was around one year. The patients were healthy apart from diabetes mellitus. All cases had negative tests for AIDS virus. The clinical diagnosis was established by histopathological examination. All patients had wide spread rash but mainly involving both limbs. No systemic involvement was detected as assessed by clinical examination and different investigations related to the disease. The rash was non-itchy and consisted of dusky red papules, nodules and plaques. While edema of feet were noticed in all patients and this edema was important feature of disease activity and of diagnostic value of Kaposi sarcoma.

The nature and target of this study were explained for each patient. Formal consent was taken from each patient before starting the therapy, after full explanation about the nature of the disease, course, and the options of treatment, follow up, prognosis, complications and the need for pre and post treatment photographs. Also, the ethical approval was given by the scientific committee of the Scientific Council of Dermatology \& Venereology-Iraqi Board for Medical Specializations. Color photographs for all patients were performed by 8 megapixels camera of mobile Samsung Galaxy 5, in the same place and distance with fixed illumination.

These patients were treated by oral zinc sulfate capsule (by Thomas Bekar India) $100 \mathrm{mg}$ three times per day and oral propranolol (Astra Zeneca UK Limited) $20 \mathrm{mg}$ three times per day together with $30 \%$ topical zinc sulfate solution twice a day for $6-12$ months. Thirty percent (W/V) zinc sulfate solution is prepared by dissolving 30 grams of zinc sulfate crystals $\left(\mathrm{ZnSO}_{4} \cdot 7 \mathrm{H}_{2} \mathrm{O}=287.54\right.$, by Thomas Be- 
kar India) in $100 \mathrm{ml}$ of distilled water, and kept in clean container at the room temperature of hospital. Patients were instructed to apply this preparation topically on their lesions twice a day for 6 - 12 months using cotton applicator.

\section{Results}

The response to therapy started around few weeks and was obvious after one month (Figures 1-3). The old lesions were improved and disappeared within few weeks leaving post inflammatory hyperpigmentation. But during the course of therapy there were few lesions appeared but also disappeared during follow up. The disease remained static and no progression appeared and no systemic involvement was noticed. Also edema of the legs and feet which is a sign of activity of the disease was subsided. No important systemic or topical side effects were observed during therapy.

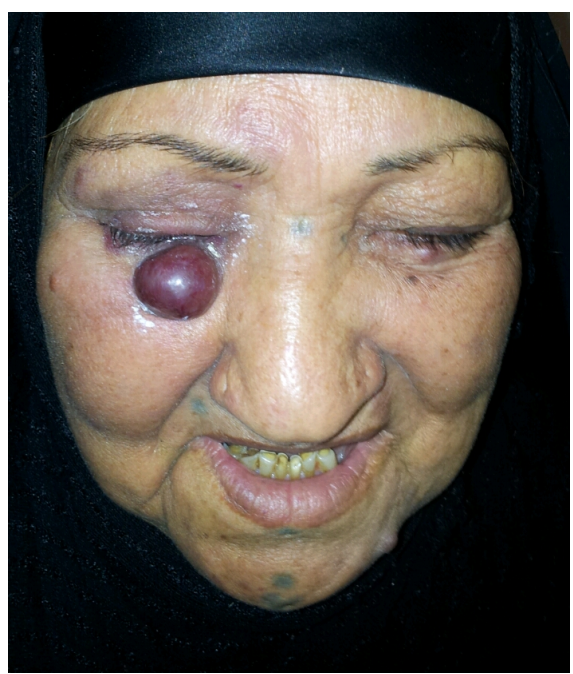

(a)

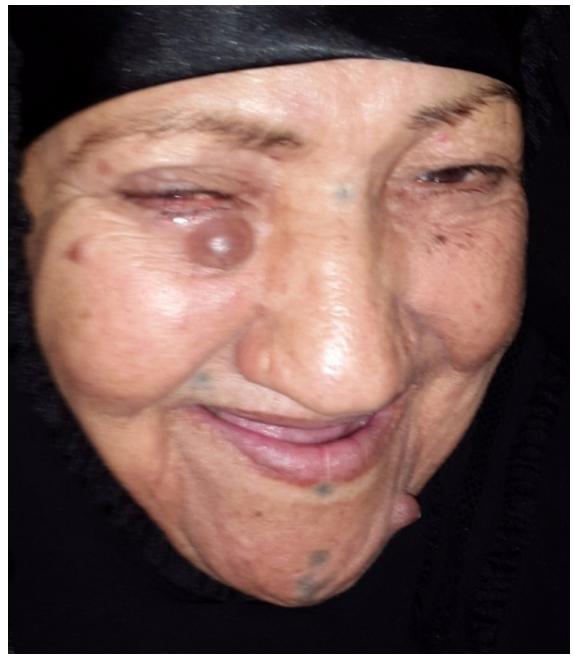

(b)

Figure 1. (a) Sixty five years old female patient with Kaposi's sarcoma before therapy; (b) The same patient after 2 months of therapy. 


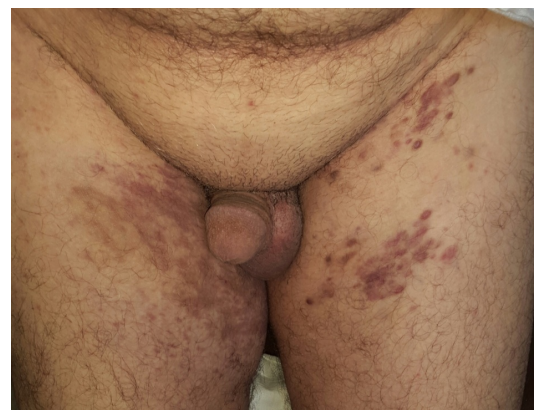

(a)

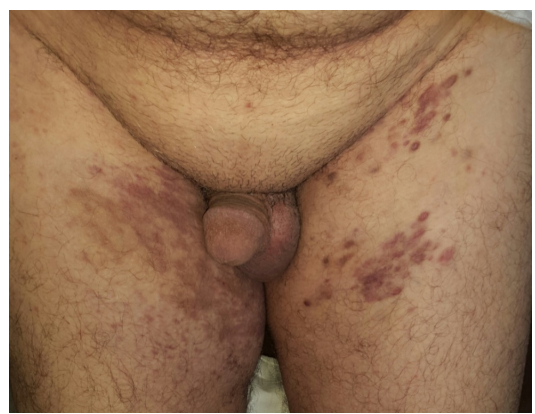

(b)

Figure 2. (a) Sixty years old male patient with Kaposi's sarcoma before therapy; (b) The same patient after one month of therapy.

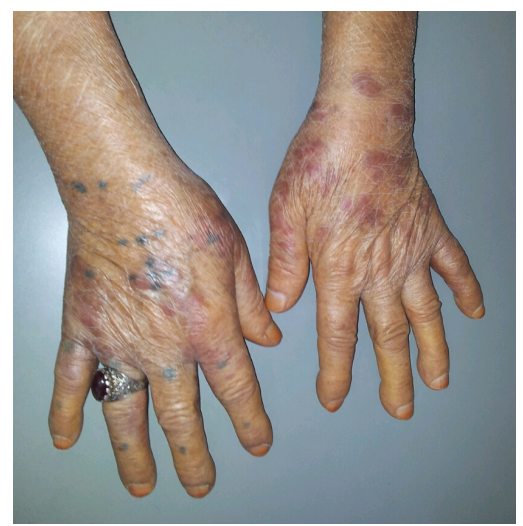

(a)

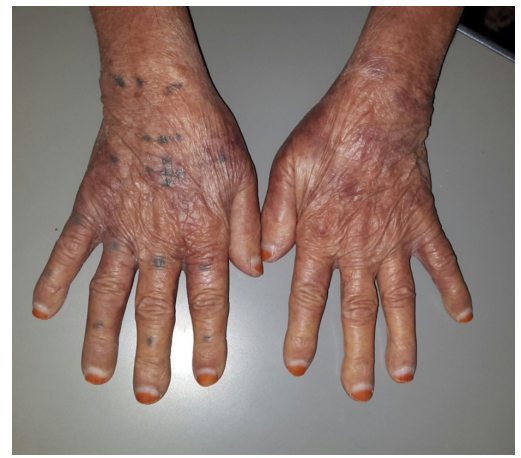

(b)

Figure 3. (a) Seventy five years old female patient Kaposi's sarcoma before therapy; (b) The same patient after two months of therapy. 


\section{Discussion}

Many topical and systemic therapies are available for KS but none of them satisfactory but only suppressive and might resolve completely when Kaposi sarcoma is induced by drugs like those immunosuppressive drugs that are used to prevent kidney transplantrection [1] [5] [6]. The present report showed new ideas of treatment of this disease by combining two therapeutic drugs of different mechanism of actions as propranolol, an on selective b-AR antagonist, has been hypothesized to act via vasoconstriction, inhibition of angiogenesis, and induction of apoptosis, thus preventing the progression and spread of KS [7]. While zinc sulfate works through its antimicrobial, immunomodulation and cytotoxic actions, hence they work together to suppress KS and prevent its progression, resolution of old lesions and stop new lesions [8] [9] [10]. In addition, both drugs are safe non-costly and without important side effects unless there is some contraindications for these drugs. The present work had confirmed that this combined treatment had suppressive actions with satisfactory results.

\section{Conclusion}

We strongly recommend further extensive studies through multiple medical centers to confirm the present interesting findings as these drugs gave promising hope in controlling this disease.

\section{Disclosure}

This study was an independent study and not funded by any drug companies.

\section{Conflicts of Interest}

The authors declare no conflicts of interest regarding the publication of this paper.

\section{References}

[1] Calonje (2010) Soft-Tissue Tumours and Tumour-Like Conditions. In: Burns, T., Breathnach, S., Griffiths, C. and Cox, N., Eds., Rook's Textbook of Dermatology, 8th Edition, Wiley-Blackwell, 56, 33-37.

[2] Weiss, R.A., Whitby, D. and Talbot, S. (1998) Human Herpesvirus Type 8 and Kaposi's Sarcoma. JNCI Monographs, 23, 51-54. https://doi.org/10.1093/oxfordjournals.jncimonographs.a024173

[3] Al-Saleem, T., Sharquie, K.E., Alash, N., Naimi, A. and Sha'arbaf, H.H. (1984) Kaposi's Sarcoma in Iraqi Patients. Proceedings of the First Scientific Conference of Medical College, University of Baghdad, Baghdad, 24 April 1984.

[4] Al-Waiz, M., Sharquie, K.E. and Al-Hamdani, G.A. (2003) Un Upsurge of New Cases of Kaposi's Sarcoma in Iraqi Patients. Saudi Medical Journal, 24, 224-225.

[5] Appero, J.W., Conant, M.A., Wolfe, S.F. and Berger, T.G. (1993) Kaposis Sarcoma. Epidemiology, Pathogenesis, Histology, Clinical Spectrum, Staging Criteria and Therapy. Journal of the American Academy of Dermatology, 28, 371-395.

[6] North, P.E. and Kincannon, J. (2012) Vascular Neoplasms and Neoplastic-Like Pro- 
liferations. In: Bolognia, J.L., Jorizzo, J.L. and Schaffer, J.V., Eds., Dermatology, 3rd Edition, Elsevier Saunders, 114, 1932-1935.

[7] Storch, C.H. and Hoeger, P.H. (2010) Propranolol for Infantile Heamangiomas: Insight into the Molecular Mechanism of Action. British Journal of Dermatology, 163, 269-274. https://doi.org/10.1111/j.1365-2133.2010.09848.x

[8] Sharquie, K.E., Khorsheed, A.A. and Al-Nuaimy, A.A. (2007) Topical Zinc Sulphate Solution for Treatment of Viral Warts. Saudi Medical Journal, 28, 1418-1421.

[9] Sharquie, K.E., Najim, R.A., Farjou, I.B. and Al-Timimi, D.J. (2001) Oral Zinc Sulphate in the Treatment of Acute Cutaneous Leishmaniasis. Clinical and Experimental Dermatology, 26, 21-26. https://doi.org/10.1046/j.1365-2230.2001.00752.x

[10] Prasad, A.S. (2009) Zinc: Role in Immunity, Oxidative Stress and Chronic Inflammation. Current Opinion in Clinical Nutrition \& Metabolic Care, 12, 646-652. https://doi.org/10.1097/MCO.0b013e3283312956

[11] Yamaoka, J., Kume, T., Akaike, A. and Miyachi, Y. (2000) Suppressive Effect of Zinc Ion on iNOS Expression Induced by Interferon-Gamma or Tumor Necrosis Factor-Alpha in Murine Keratinocytes. Journal of the Dermatological Science, 23, 27-35. https://doi.org/10.1016/S0923-1811(99)00062-6

[12] Schwartz, J., Marsh, R. and Draelos, Z. (2005) Zinc and Skin Health: Overview of Physiology and Pharmacology. Dermatologic Surgery, 31, 837-847. https://doi.org/10.1111/j.1524-4725.2005.31729

[13] Theocharis, S.E., Margeli, A.P. and Koutselinis, A. (2003) Metallothionein: A Multifunctional Protein from Toxicity to Cancer. The International Journal of Biological Markers, 18, 162-169. https://doi.org/10.1177/172460080301800302

[14] Meerarani, P., Ramadass, P., Toborek, M., Bauer, H.Ch., Bauer, H. and Hennig, H. (2000) Zinc Protects against Apoptosis of Endothelial Cells Induced by Linoleic Acid and Tumor Necrosis Factor a1-3. The American Journal of Clinical Nutrition, 71, 81-87.

[15] Biyukavir, M., Gurol, A., Karabulut, A., Budak, G. and Karaem, M. (2005) The Role of Iron and Zinc in Chemotherapy Induced Alopecia. Journal of Quantitative Spectroscopy \& Radiative Transfer, 95, 256-261.

[16] Park, H., Kim, C.W., Kim, S.S. and Park, C.W. (2009) The Therapeutic Effect and the Changed Serum Zinc Level after Zinc Supplementation in Alopecia Areata Patients Who Had a Low Serum Zinc Level. Annals of Dermatology, 21, 142-146. https://doi.org/10.5021/ad.2009.21.2.142 